\title{
DOES USER SATISFACTION WITH HOME-BASED SERVICES INFLUENCE OLDER PEOPLE'S QUALITY OF LIFE? --EVIDENCE FROM THE SURVEY IN BEIJING
}

\author{
RUI KANG, GEORGE LEESON, KENNETH HOWSE
}

\begin{abstract}
:
There is high need for the Chinese government to build a perfect welfare system to cope with the challenge of population ageing at this stage. The goal of this paper is to achieve policy implications how to provide a better life for older people from the perspective of care and service of high quality. We outline the relationship between current quality of life (QOL) of older people in Beijing and their satisfaction with home-based services. We make the hypothesis that older people's QOL is positively correlated with user satisfaction with home-based services. Essentially, older people who are satisfied with the home-based services are more likely to achieve a high QOL. The outcome from multiple regression analyses shows the trend that QOL is positively influenced by user satisfaction with the personal care services. We also find that the above services are the substitution for family support with regards to the QOL, which depends on the number of recipient's children and their household expenditure per person. However, there is no relationship found between the QOL and satisfaction with the housekeeping services. The study supports the importance of providing health and diagnosed services as well as spiritual support in order to ensure high quality of older people's rest lives. At the same time, flexible and hierarchical public funding or subsidies should be better targeted for the older people from different family backgrounds.
\end{abstract}

\section{Keywords:}

older people, QOL, satisfaction, personal care

JEL Classification: $138, \mathrm{J14}, \mathrm{J} 16$

\section{Authors:}

RUI KANG, School of Labour Economics, Capital University of Economics and Business, China, Email: kangruideemail@126.com

GEORGE LEESON, Oxford Institute of Population Ageing, University of Oxford, United Kingdom,

Email: george.leeson@ageing.ox.ac.uk

KENNETH HOWSE, Oxford Institute of Population Ageing, University of Oxford, United Kingdom, Email: kenneth.howse@ageing.ox.ac.uk

\section{Citation:}

RUI KANG, GEORGE LEESON, KENNETH HOWSE (2018). DOES USER SATISFACTION WITH HOME-BASED SERVICES INFLUENCE OLDER PEOPLE'S QUALITY OF LIFE? --EVIDENCE FROM THE SURVEY IN BEIJING. International Journal of Social Sciences, Vol. VII(2), pp. 36-61., 10.20472/SS.2018.7.2.003 


\section{Introduction}

China is facing a rigorous social problem with a growing ageing population. According to the statistical data collected by the Ministry of Civil Affairs of China, the national population aged 65 and over has climbed to 106.36 billion by the end of 2017, which accounts for $8.05 \%$ of the total population. The old-age dependency ratio of 65 years old and over is as high as $11.1 \%$, which means 8 or 9 young people need to support an old person. ${ }^{1}$ Therefore, the whole society needs to meet the challenge to ensure older people's lives and well-being. As a consequence, it is of significant importance to identify the available ways to improve the QOL of older people. The Chinese central government and its functional sectors have put forwards various types of policy documents to prompt home-based services for older people in order to make the remainder of their lives to have the highest quality possible. As Beijing is the capital city of China, its home-based services for older people can be seen as a leader all around the country, which started in the 1990s with the advent of population ageing. Based on the central policy of China, home care is the basic way to support the ageing system. According to the old-age caring goal "9064" pattern of the Beijing government, there will be $90 \%$ of the older people relying primarily on home care in $2020 .^{2}$ The aim of homebased services for older people is to make these older people enjoy their rest lives at home. This type of service served approximately 2.96 million older people in 2016 according to data from the Beijing Municipal Civil Affairs Bureau. ${ }^{3}$ As a result, the demand of home care is in a rapid growth in the near future. As neither the public nor the private sector can meet the challenge of service provision separately, the government encourages the private sector to participate, in imitation of western countries. A substantial port of home-based services for older people are provided by the private sector, whereas the local authority is in charge of the responsibility of rulemaking, grant, monitoring and so on. There is a cooperative relationship between the government and the businesses due to the great demand of older people, which is called Public-Private Partnership (PPP). The private sector has joined the membership through the way of competitive tendering, with funds and other help from the government to construct the basic facilities. Meanwhile, the local authority of every district in Beijing issues a card of subsidy to older people aged 60 and over living in the area. The card can only be used in the service sellers, which is designated by the local 
authority with the contract. The local authority is responsible of topping up the card with 100 yuan RMB every month for. Generally, there are two types of home-based services that needed by older people and can also be purchased in the market of Beijing, including housekeeping service and personal care services. These can help older people with activity of daily living (ADLs). With an increase in age, there is a physical function decline in older people, resulting in the need for personal care. Caregivers help older people to take baths, conduct daily physical examinations as well as providing first aid and rehabilitation nursing. Spiritual consolation is conducted with the talking, psychological counseling and companionship accompany.

A large body of research focuses on the QOL of older people in recent decades. QOL is related to the self-evaluation of older people about their daily lives. It is subjective, depending on the perception and comprehension of each individual. (Zilla 1974; Hickey, et al., 1991) 45 Therefore, the definition and measurement of QOL should be grounded empirically in different views, taking into account the social circumstances. Various ways are used to define the QOL. Maslow (1954) created the classic models in view of human needs. 6 Psychological wellbeing and happiness were added in subsequent development. (Frank 1976; Larson 1978; Andrews 1986) ${ }^{78}$ Some studies also take the physical health and social experience into account. (Calman 1983; Bowling 2001) (10 $^{10}$ Galbraith (1965) believed that QOL includes tangible and intangible living conditions. ${ }^{11}$ According to the Boston Health Research in the United States, QOL can be measured by five items: mental health, physical health, economic ability, social relationship, and the surrounding environment. In China, scholars tend to judge the QOL using criteria in six aspects: material life, spiritual and cultural life, life quality, living environment, rights and interests as well as their own perceptions. (Cangping Wu 2002) ${ }^{12}$ Others suggest that QOL is equal to the quality of health (Min Luo, et al. 2005) ${ }^{13}$, including physical and mental health. A few people associate the QOL with the subjective feelings, such as the quality of happiness and loneliness. (Xihua Wang 2010) ${ }^{14}$

Social care services play an increasingly important role in older people's lives. They are used to help the older people with their daily activities due to the gradual loss of physical and cognitive function with ageing. Most of the scholars find that older people tend to be satisfied with home-based services. (Bailey 2007; Dale, Sævareid, Kirkevold, \& So derhamn 2010; Dale, Sævareid, Kirkevold, \& So“ derhamn 2011) 151617 On this 
basis, the study from many aspects has put forward a change in user satisfaction with different types of services and different personal characters. Some related characteristics of the services, such as the type of care received (Crow, et al. 2002), the content of services (Curtis, et al. 2005) and the number of choices for services (Chou, et al. 2003) have a close impact on user satisfaction. ${ }^{181920}$ In addition, a study by Berglund (2007) found that older people's satisfaction with home-based services depends on the staff that carry out the care, including their support, caring approach, respect for individual's opinion and so on. ${ }^{21}$ Another study demonstrated that older people tend to be more pleased when they come across the staff with suitable knowledge, skills and competence. (Woodward, et al. 2004)22 Finally, satisfaction with social care services varies from person to person due to differences in personal character. Crow (2002) and his team found that it is considerably influenced by an individual's health status. The subsequent articles further present a close relationship of poor satisfaction with illness, pain, distress and anxiety. (Rubinstein 2000; Rahmqvist 2001; Bair et al. 2007) 2324

Research based on the older people's QOL and their satisfaction with home-based services has developed separately for many years. However, articles related to the connection between them are rare. As a result, the association between the above two objectives remains a neglected but increasingly important area of research and social policy. Several articles based on the public service demonstrate a positive connection between QOL and satisfaction with the services. All that is missing is having members of general population being used for the population of study, instead of focusing only on older people. Indeed, the ultimate goal of the Beijing government in providing services for older people is to improve their QOL and well-being. However, certification on this judgment is sparse.

Against this background, we aim to find out the relationship between the QOL and satisfaction with home-based services among older people. This paper includes the following parts: Section 2 shows the hypotheses and research questions based on Talcott Parsons's Theory of Social System and constructs an empirical model to discuss how user satisfaction affects the QOL of older people; Section 3 offers data from China's survey and examines whether there is a positive or negative relationship between older people's QOL and their satisfaction with home-based services. In addition, there is 
verification on different functions user satisfaction has on QOL when it comes to different family backgrounds. Section 4 offers some main findings and discussion on policy implications.

\section{Methodology}

\section{Source of Data}

This paper uses data from the Survey on the Use of Home-based Care(SUHC) by the Capital University of Economics and Business in the summer of 2015. The survey collected home-based care information of the older people aged 60 and over from five districts of Beijing, including Xicheng District, Dongcheng District, Fengtai District, Chaoyang District and Haidian District. SNHC is designed to evaluate older people's actual feelings when using home-based service in addition to assessment of their QOL. This was conducted by self-reported questionnaires and interviews. A questionnaire was administered through a face-to-face interview in the district office. Furthermore, we conducted a household survey among the older people with mobility problems. There were 1050 respondents interviewed and 698 copies of questionnaires retrieved. The analysis in this paper draws on three modules of SUHC: demographic information, older people's evaluation of QOL and satisfaction with 17 types of home-based services. In addition, we arranged 150 participants to be separately interviewed with their response being an important part of our study.

\section{Hypotheses and Empirical Models}

According to Talcott Parsons's Theory of Social System, people who are not competent to help themselves or face the risk of worsening, suffering, death or fundamental disturbances are unable to find the positive satisfaction in their lives. People with these specific features are said to have the role of being sick. Professional and technical help and care are thought to drive the vulnerable group from incapacity to function normally, which can be seen as a remedy for their loss. They feel better with themselves and the surrounding environment when the performance of treatment takes place. ${ }^{25}$ Essentially, as people age gradually, there is decline in their body functions. When this is combined 
with the impairment of choric diseases, they struggle to deal with the daily living and social relationships. A system of home-based services is one of the most effective approaches to change the role of older people from a sick role to a better situation.

We hypothesized that if older people feel satisfied with home-based services, they achieve more utility and the QOL increases accordingly. In other words, greater satisfaction of older people with home-based services, results in a higher QOL evaluated for themselves. Similarly, older people who give a lower scare for evaluate lower on home-based services they have used are more likely to have lower QOL compared to those who are more satisfied with the services. Hypotheses concerning personal character follow a similar pattern. As a result, we can create the QOL equation as follows:

$$
Q O L_{i}=\beta_{0}+\beta_{1} * H k_{i}+\beta_{2} * P c_{i}+\beta_{3} * \operatorname{Demographi}_{i}(i=1,2 \ldots, N)
$$

Where $Q O L$ is the older people's evaluation of their QOL. $H k$ and $P c$ represent user satisfaction with the housekeeping and personal care services. Demographic includes age, gender, marriage, health etc.; and $\mathrm{N}$ is the sample size.

Based on the above analysis, we aimed to find out whether there was difference for the research subjects if they were from different backgrounds. In terms of the Social Structure of the Theory of Social System, caring for the sick or vulnerable group is not necessarily the responsibility of all societies. The organization is nowadays replacing family in the context of care. Furthermore, the need for informal care will be considerably reduced by better targeting of home-based care services. It is crucial to know that homebased services are the substitution for support from older people's spouse and other members of the family, especially their adult children who accompany them. Services contribute considerably to older people's QOL when they lack support from adult children and with regards to affordability. On the contrary, services have no impact on their QOL when it comes to the older people who have more children or economic resources. As a result, we assume that user satisfaction has an important influence on the QOL of older people who are disadvantaged with fewer children or lower household expenditure per person, which can also be tested using Equation (1) after dividing samples into different groups. 


\section{Samples}

The following criteria are used for inclusion: individuals have to be beyond the age of 60 years old, live at home, have received one or more types of home-based services and have the ability to make an assessment. To make the analysis outcome more persuasive, we choose the recipients across the relevant age span, both genders (approximately each gender accounted for half on average), and with different backgrounds. The characteristics of Participants can be seen in Appendix A, while illustration of variables are shown in Appendix B.

\section{Outcome Variables}

QOL is assessed using the form of a validated version, which is based on medical outcomes from the short study designed by Stewartse in 1988. The form shows 13 items that measure five main scales of the routine life of older adults apart from the QOL itself. It can be separated into physical health, mental health, social relationship, economic ability and the surrounding environment. QOL is revealed using a series of questions from the scale, such as, "overall, how would you think of your quality of life". Response options are performed as "very poor", "poor", "medium", "good" and "very good". These are scored 1-5. We obtained the aggregate score of each concept. The aggregate score provides a common denominator by which we can judge the outcomes by translating several evaluations into one measure. The aggregate score of each item and that for different groups of people can be shown in Table 1 and Appendix A, separately.

Table1. Evaluation of the QOL on average $(\mathrm{N}=698)$.

\begin{tabular}{ccccccc}
\hline & \multicolumn{3}{c|}{ Physical health } & \multicolumn{2}{c}{ Social relationship } \\
\hline $\begin{array}{c}\text { Health } \\
\text { status }\end{array}$ & $\begin{array}{c}\text { Abundant } \\
\text { energy }\end{array}$ & $\begin{array}{c}\text { Sleep } \\
\text { situation }\end{array}$ & $\begin{array}{c}\text { Medical } \\
\text { dependence }\end{array}$ & Mobility & $\begin{array}{c}\text { Interpersonal } \\
\text { relationship }\end{array}$ & Family \\
friction
\end{tabular}




\begin{tabular}{|c|c|c|c|c|c|c|}
\hline \multicolumn{3}{|c|}{ Mental health } & \multirow{2}{*}{$\begin{array}{c}\text { Economic } \\
\text { ability } \\
\text { Enough } \\
\text { money }\end{array}$} & \multicolumn{2}{|c|}{ Surrounding environment } & \multirow{2}{*}{ QOL } \\
\hline $\begin{array}{c}\text { Life } \\
\text { pleasure }\end{array}$ & $\begin{array}{l}\text { Leisure } \\
\text { activities }\end{array}$ & $\begin{array}{l}\text { Negative } \\
\text { feelings }\end{array}$ & & $\begin{array}{l}\text { Place of } \\
\text { residence }\end{array}$ & Health service & \\
\hline 3.15 & 3.24 & 3.86 & 2.61 & 2.93 & 3.18 & 3.28 \\
\hline
\end{tabular}

The evaluation of six parts of $\mathrm{QOL}$ is clearly shown. The highest score appeared in the social relationship. Compared with physical and mental health, older people feel more satisfied with their interpersonal relationship with family members and friends. The greater dissatisfaction shown was related to the economic ability, with most of the recipients suggesting that they do not have enough money to maintain their daily life. It can be inferred obviously that the health status is at moderate levels, whether this is physical or mental health. The assessment of QOL shows the same features. For negative feelings, the question was "Are you struggling with negative feelings". For this item, a lower score means less agreement with the statement, and hence, better mental health.

\section{Independent Variables}

In our survey, we chose the 17 most frequently used types of services, which can be divided into housekeeping and personal care according to their different functions. Housekeeping can assist older people who struggle to get practical tasks done in the household, which includes the hourly worker, shopping, laundry, removing pipeline dredge, appliance repair, indoor cleaning in addition to water and electricity installation maintenance. Personal care is intended for older people who are physically disabled, mentally disabled or those with mental health illnesses. Personal care supports these people with ADLs that may be impossible to do alone, or have become more difficult, which includes attendance at a day center; assistance with drug administration; haircut; bath assistance; psychological counseling; chatting and recreation; family health services; skilled care services; periodic health examination; and accompanied doctor visits. Uses of different types of services are shown in the Appendix C. Satisfaction 
levels were determined based on adapted questions from our questionnaire. The satisfaction is clarified into five levels: (1) extremely dissatisfied; (2) dissatisfied; (3) medium; (4) satisfied; (5) extremely satisfied. The variables were assigned scores of 15 , with a higher number indicating a better the level of satisfaction.

In addition, life benefits of older individuals are in accordance with strong heterogeneity. Essentially, different older people choose their later life in larger utility with more consideration of their own backgrounds. Individual social demographic characteristics are also included in the statistical analysis as control variables: age, gender, marital status, and health status.

\section{Results}

\section{Data of Pre-processing}

A standard multiple linear regression was performed to verify the referred hypotheses. Due to the similarity of the aim of different services and participants' preferences, there is a great similarity among older people's feelings about different aspects of their life and their satisfaction with different services. Before the regression was performed, we conducted a Principal Component Analysis in dependent and independent variables respectively in order to delete the multi-collinearity in the models. The Principal Component Analysis was used to extract a principal component from 14 items regarding the QOL, with seven regarding satisfaction with housekeeping and ten in satisfaction with personal care.

\section{Relationship between QOL and user satisfaction with home-based services}

A standard multiple linear regression is performed to estimate the relationship between QOL evaluated by recipients and their satisfaction with home-based services. As shown in Table 2, older people's QOL is positively related to their satisfaction with personal care (coefficient of $0.009, p=0.000$ ). On the contrary, there is no significant relationship between QOL and user satisfaction with housekeeping (coefficient of $-0.124, p>0.05$ ). 
Table 2. Estimation of the effect of satisfaction with home-based services on QOL.

\begin{tabular}{|c|c|c|c|c|c|c|}
\hline & Coefficient & Standard error & $\mathrm{T}$ & $P$ & \multicolumn{2}{|c|}{$95 \% \mathrm{Cl}$} \\
\hline Satisfaction with housekeeping & -0.124 & 0.068 & -1.82 & 0.068 & -0.257 & 0.010 \\
\hline Satisfaction with personal care & 0.009 & 0.003 & 3.05 & 0.000 & 0.003 & 0.015 \\
\hline Age & 0.002 & 0.001 & 1.97 & 0.003 & 0.000 & 0.004 \\
\hline \multicolumn{7}{|l|}{ Gender(Male= Control group) } \\
\hline Female & 0.001 & 0.001 & 1.02 & 0.308 & -0.001 & 0.003 \\
\hline \multicolumn{7}{|c|}{ Marital status(Married = Control group) } \\
\hline Non-married & 0.465 & 0.196 & 2.37 & 0.018 & 0.081 & 0.849 \\
\hline Health status & 0.903 & 0.430 & 2.10 & 0.004 & 0.060 & 1.746 \\
\hline $\mathrm{N}$ & \multicolumn{6}{|c|}{698} \\
\hline Adjusted $\mathrm{R}^{2}$ & \multicolumn{6}{|c|}{0.783} \\
\hline$P$ & \multicolumn{6}{|c|}{0.000} \\
\hline
\end{tabular}

Relationship between older people's QOL and satisfaction with home-based services considering the substitution effect of family support

As shown in Appendix $A$, the median of the number of children and the household expenditure per person is 1.16 and 2,307.52 yuan, respectively. We divided the samples 
into two groups using the median of the number of children and conducted regression analysis separately. This was also applied in the household expenditure per person. The following table presents the results from an OLS regression in which the dependent variable is influenced by different family backgrounds.

There is no verified relationship between the older people's QOL and their evaluation on the housekeeping service whether in the full sample other models.

In Table 3, the estimated coefficients of the explanatory variables in Columns (2) and (3) indicate the difference in the relationship between QOL and user satisfaction with personal care for older people with different numbers of children. It is significant for the impact of older people's feelings about personal care services on their QOL if they have one or no child. That is to say, those who reported having les than one child are more likely to report a higher QOL as they are more satisfied with personal care services they achieve (coefficient of $0.022, p=0.000$ ). However, there is no relationship between the above variables when it comes to the older person who is accompanied by more than one adult children(coefficient of $0.007, p>0.05$ ).

Similarly, as in Column (4), the recipients are the older people whose per capita household expenditure per person is more than 2,307.52 yuan every year, with all other participants shown in column (5). Despite the exponential relationship between variables in the full model, including both groups of people with different economic abilities (coefficient of $0.009, p=0.000$ ) and the model of people whose household expenditure per person is lower than median (coefficient of $0.019, p=0.000$ ), the significance does not occur in the sample of individuals who have a greater household expenditure per person(coefficient of $0.025, p>0.05$ ). For the majority of the group with higher payment ability, the evaluation of QOL is still stable, whether they are satisfied with the personal care services or not. 
Table 3. Estimation of the effect of satisfaction with home-based services on QOL of older people with different family backgrounds.

(1)

\begin{tabular}{c}
\hline Sample \\
Satisfaction \\
with
\end{tabular}

(2)

(3)
(4)

(5)

housekeeping

$\begin{array}{lll}-0.124 & 0.101 & -0.037 \\ (0.068) & (0.484) & (0.438)\end{array}$

0.179

0.276

Number of Number of

children is children is

Household Household

expenditure expenditure

per person per person

$\begin{array}{cc}\text { above } & \text { blow } \\ \text { sample } & \text { sample } \\ \text { median } & \text { median }\end{array}$

is above is blow

sample sample

median median

$\begin{array}{cccccc}\text { Satisfaction } & 0.009^{* * *} & 0.007 & 0.022^{* * *} & 0.025 & 0.019^{* * *} \\ \text { with personal } & (0.003) & (0.518) & (0.003) & (0.811) & (0.000) \\ \text { care } & & & & & \\ & & & & & \\ & & & & & \\ \text { Age } & 0.002^{*} & 0.007^{* * *} & 0.004^{* * *} & & 0.010 \\ & (0.001) & (0.003) & (0.017) & (0.040) & (0.931)\end{array}$

Gender

(Male $=$ Control group)

$\begin{array}{lccccc} & 0.001 & 0.012 & 0.001 & 0.008 & 0.012 \\ \text { Female } & (0.001) & (0.989) & (0.757) & (0.230) & (0.287)\end{array}$


Marital status

(Married $=$ Control group)

\begin{tabular}{|c|c|c|c|c|c|}
\hline \multirow{2}{*}{ Non-married } & $0.465^{*}$ & $0.655^{* *}$ & $0.569^{* *}$ & $0.393^{* * *}$ & $0.258^{* * *}$ \\
\hline & $(0.196)$ & $(0.000)$ & $(0.000)$ & $(0.000)$ & $(0.001)$ \\
\hline Health & $0.001^{*}$ & 0.002 & 0.011 & $0.270^{*}$ & $0.003^{* * *}$ \\
\hline status & $(0.000)$ & $(0.669)$ & $(0.384)$ & $(0.088)$ & $(0.734)$ \\
\hline $\mathrm{N}$ & 698 & 349 & 349 & 349 & 349 \\
\hline Adjusted $\mathrm{R}^{2}$ & 0.733 & 0.793 & 0.706 & 0.800 & 0.696 \\
\hline$P$ & 0.000 & 0.000 & 0.000 & 0.000 & 0.000 \\
\hline
\end{tabular}

Standard errors in parentheses. ${ }^{\star} p<0.05,{ }^{* *} p<0.01,{ }^{* \star *} p<0.001$.

\section{Conclusions}

\section{Main Findings}

The purpose of this study was to investigate the relationship between older people's QOL and their satisfaction with home-based services. A remarkably positive relationship was found between QOL and satisfaction with the personal care services. However, user satisfaction with housekeeping services was not found to have a significant effect on individual's QOL, which refutes our original hypotheses.

In addition, we also examine the function of personal care services with regards to different family backgrounds. The results of regression with different variables show that the above services considerably increase older people's QOL if they are accompanied 
with fewer children or have less household expenditure. By contrast, the function of the services becomes redundant with the additional family support. As a result, we can conclude that these services can be seen as a substitution for the familial care that is provided by their children or economic resources of the whole family.

\section{Discussion}

First of all, the body and organ function of older people declines with age, which finally results in the inevitable deterioration of health. Therefore, it can be inferred that more attention should be placed on prevention of ordinary inconvenience or discomfort at old age. As stated above, personal care consists of medical care and emotional care services, which can enable older people to live as independently as possible in their own homes. Personal care services, not housekeeping, are in most needed by older people in Beijing due to its great influence on their living conditions. This is related to the level of China's economic development and people's standard of living. Individuals focus on themselves first and then pay attention to the surrounding environment that housekeeping can enhance according to the limited resources they own.

Findings from this study suggest that older people appreciate the medical services, including family health services and skilled care services. Home diagnosis and treatment services for the disabled and partially disabled older people reduce the difficulties they would experience if they had to visit the hospital. Relatively sophisticated nursing greatly enhances the possibility of older patients to be treated, which usually aims to ensure the basic medical needs. Thus, they feel better with the above services by which they can improve their health status, which eventually contributes to high QOL. Furthermore, QOL is satisfying entertainment activities because it gives older people an emotional boost to spend time with their contemporaries. The phenomenon can be explained that emotional support is becoming increasingly important as the number of children providing companionship decreases in modern society. As older people mentioned in the interview, they are rich in their material life but poor in the spiritual life. A lot of interviewees stated that they were not visited by their family members as much as they would like to. With such value placed on social relationships, it is important to have prevention of loneliness through access to company and entertainment. As a 
result, health care and emotional support provision and training for professional staff are most important tasks in the home-based service industry at this stage.

Although the scale of home-based services for older people has enlarged considerably in Beijing during the past decades, existing services are unable to provide older people with a good consumer experience at this stage. First of all, the provision of medical care services is still less than the need of older people and the gap is growing larger as the number of older individuals increases. Older people in need have to wait in line for a long time for the service they need. Some of the recipients in our survey expressed that they couldn't achieve the service in time. Secondly, some of the designated service providers' facilities are too simple and are not as functional as imagined due to limited economic ability of the private organization and the shortage of government funding support. At last, most of the service providers are not equipped with professional staff so the diverse needs of older people cannot be fulfilled. Due to the absence of formal training system, the shortage of professional skill talent is rather serious.

Furthermore, although we found the relationship between older people' assessment of QOL and evaluation on the personal care services, there is a large disparity between different groups with different family backgrounds. The majority of older people in our survey suffer from the unavailability to keep routine life partially or totally. To a certain extent, this is because of poor circumstances and a lack of support from their family members especially their children, which has to be substituted by the public services. It is also the reason why QOL is positively related with user satisfaction with referred services only for the specified group with fewer children. An absence of adult children reduces people's well-being at older ages and care from outside care should be added, which is in line with the possible explanation offered by Talcott Parsons. $(2013)^{25}$

Due to their importance in Beijing, home-based services are closely related with individual's affordability and their family economic conditions. Older people with care needs are therefore now considered to be consumers of home care since they are expected to make an informed choice of home care services according to resources they own. For the older people with less expenditure available, they are more likely to be in the urgent need for help from outside. Regarding the services mostly purchased 
by the government, the vulnerable group whose family has limited expenditure should be provided more subsidies or vouchers.

In conclusion, the accumulating evidence supports the hypothesis that future policies and interventions to increase older people's QOL could focus not only on providing and improving professional medical care but also on the spiritual support and relevance of resources among community building process. With the development of the times, the needs of older people are no longer just food and clothing. In order to pursue higher QOL, they need to be helped in their pursuit of more long-term health care and maintaining a higher spiritual demand, which can be closely combined with Maslow's Hierarchy of Needs. ${ }^{26}$ With complementary support from older people's children and personal care services, one of the policy implications that deserves mentioning is the great need for government to create the hierarchical support policies in accordance with different family backgrounds. For subsequent practical work, it's better to test what type of care adult children can provide and older people's ability to pay for services required. More importantly, in order to ensure all older people have access to a better retirement life, more attention should be placed on the requirements of the consumer population in the low hierarchy. Later on, it is necessary to train professionals and educate caregivers to fill the talent gap in the field of home-based services in order to achieve a higher quality of services for the older people. It is necessary for the government to help the weakly developed private providers to improve skills and constructions.

\section{Limitations}

First, all the variables described in our study are subjective evaluations by the older people from different backgrounds. Therefore, their perceptions of the QOL might not be exactly accurate and may eventually affect the persuasiveness of the analysis outcomes. Furthermore, there are limitations to some of the measurements in the small sample variables. Recipients are unable to express their satisfaction with the services they haven't used before so that their separate views cannot show the ideas of all respondents. It might be helpful to expand the probe and increase sample size in the future. 
Acknowledgments: This research is supported by the China Scholarship Council. The first author would like to appreciate the studying experience provided by the Oxford Institute of Population Ageing and would like to thank George Leeson from the institute for his helpful suggestions for the research. Special thanks are also due to Cheng Zhang from the University of Oxford and Hua Jiang from Capital University of Economics and Business for their kind guidance on data mining. Lastly we acknowledge the support from the SUHC team from Capital University of Economics and Business for all the data provided and interactions online.

Author Contributions: Rui Kang conceived and designed the project; Rui Kang analyzed the data; Kenneth Howse contributed analysis tools; George Leeson and Kenneth Howse modified structures of the analysis; Rui Kang wrote the paper.

Conflicts of Interest: The authors declare no conflict of interest. 
Appendix A. Characteristics of participants.

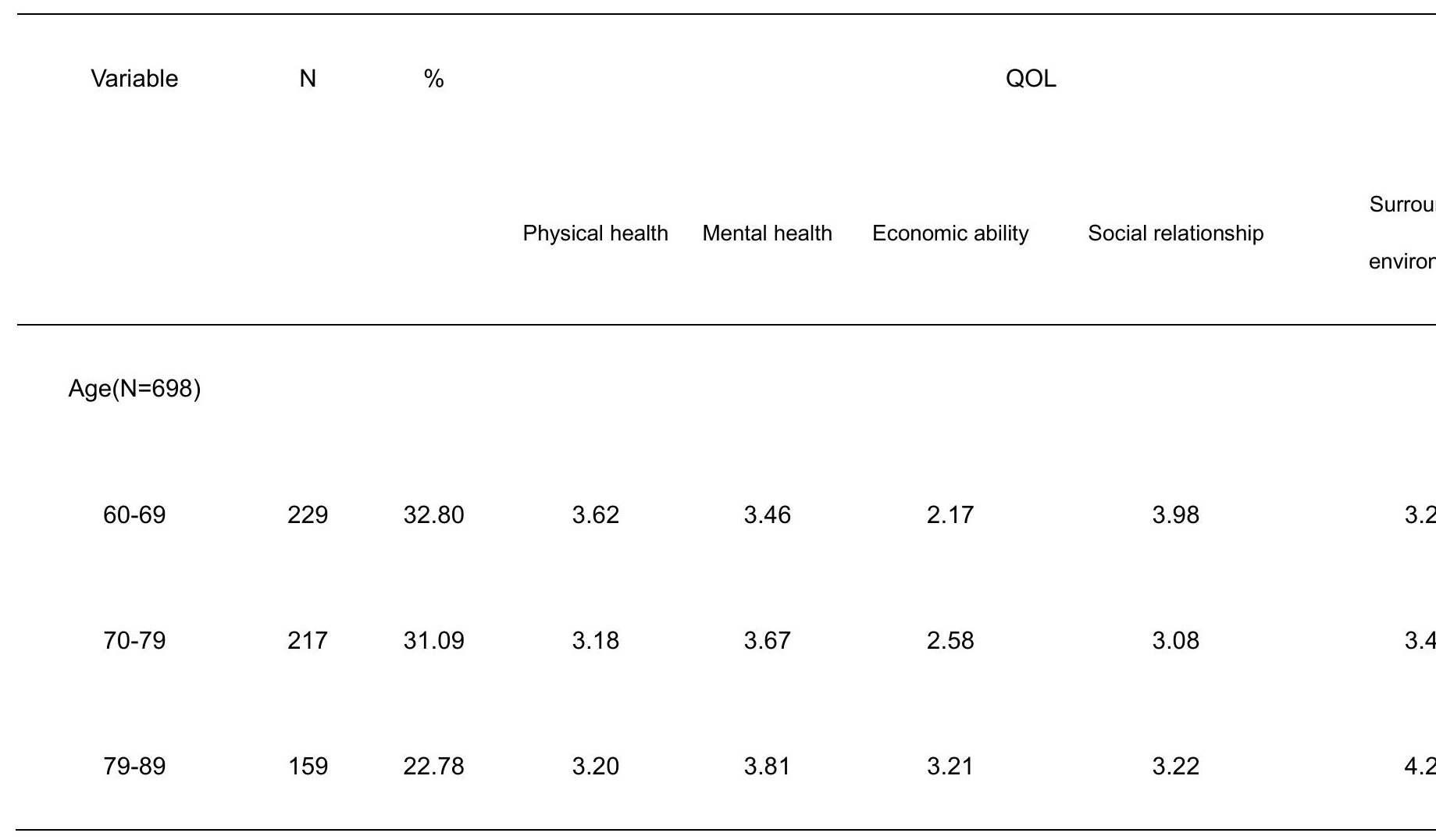


$90+$

93

13.33

4.03

4.01

4.10

3.45

Gender(N=698)

Female

356

51.00

3.27

3.56

3.51

3.23

Male

342

49.00

3.89

3.43

3.91

3.61

Marital status( $\mathrm{N}=698)$

Married

420

60.17

3.67

4.02

3.02

4.10

Non-married

278

39.82

3.49

2.97

4.4

2.74

4.2

3.2

3.8

4.1

2.9

Health status $(\mathrm{N}=698)$ 


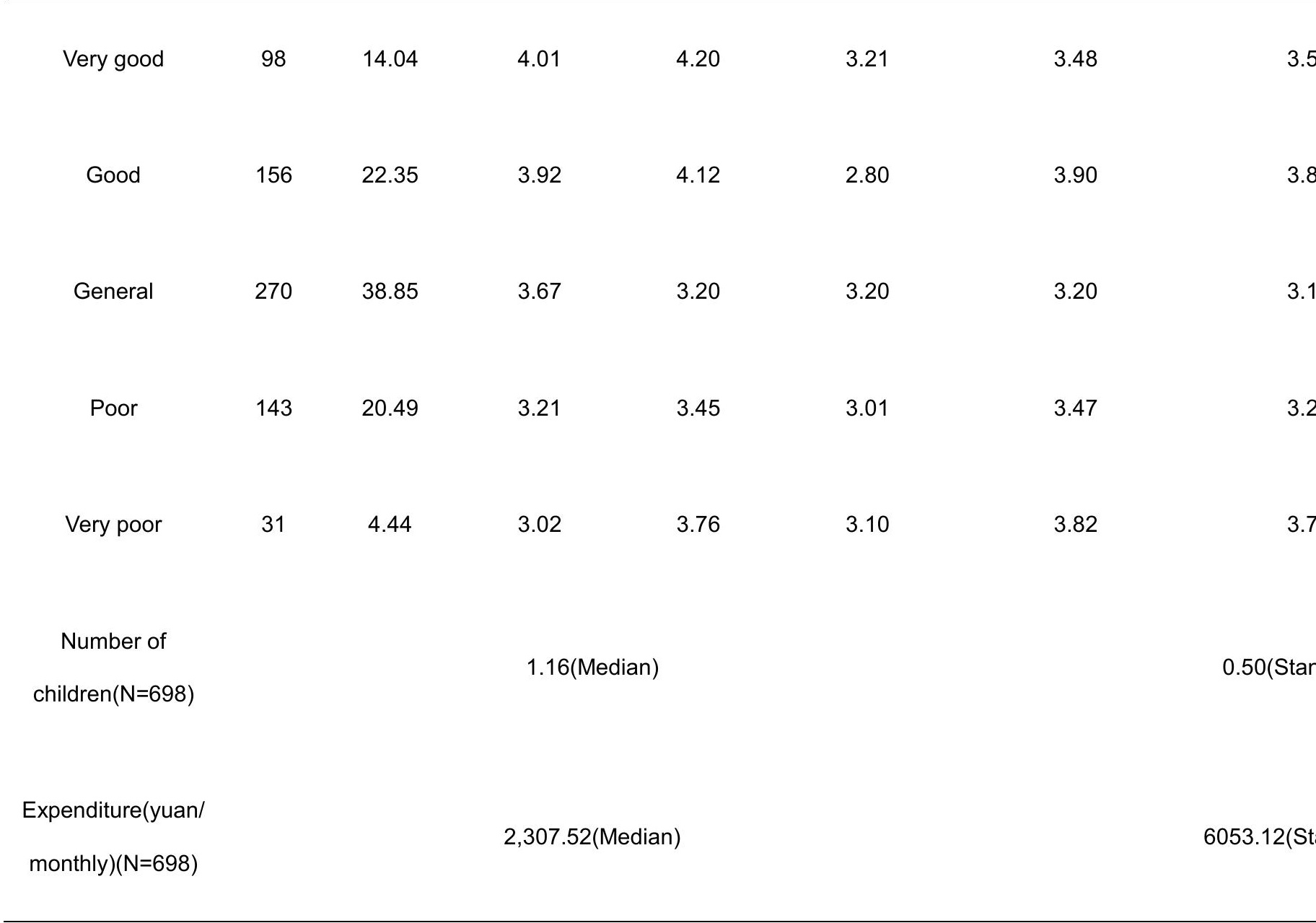


Appendix B. Illustration of the variables.

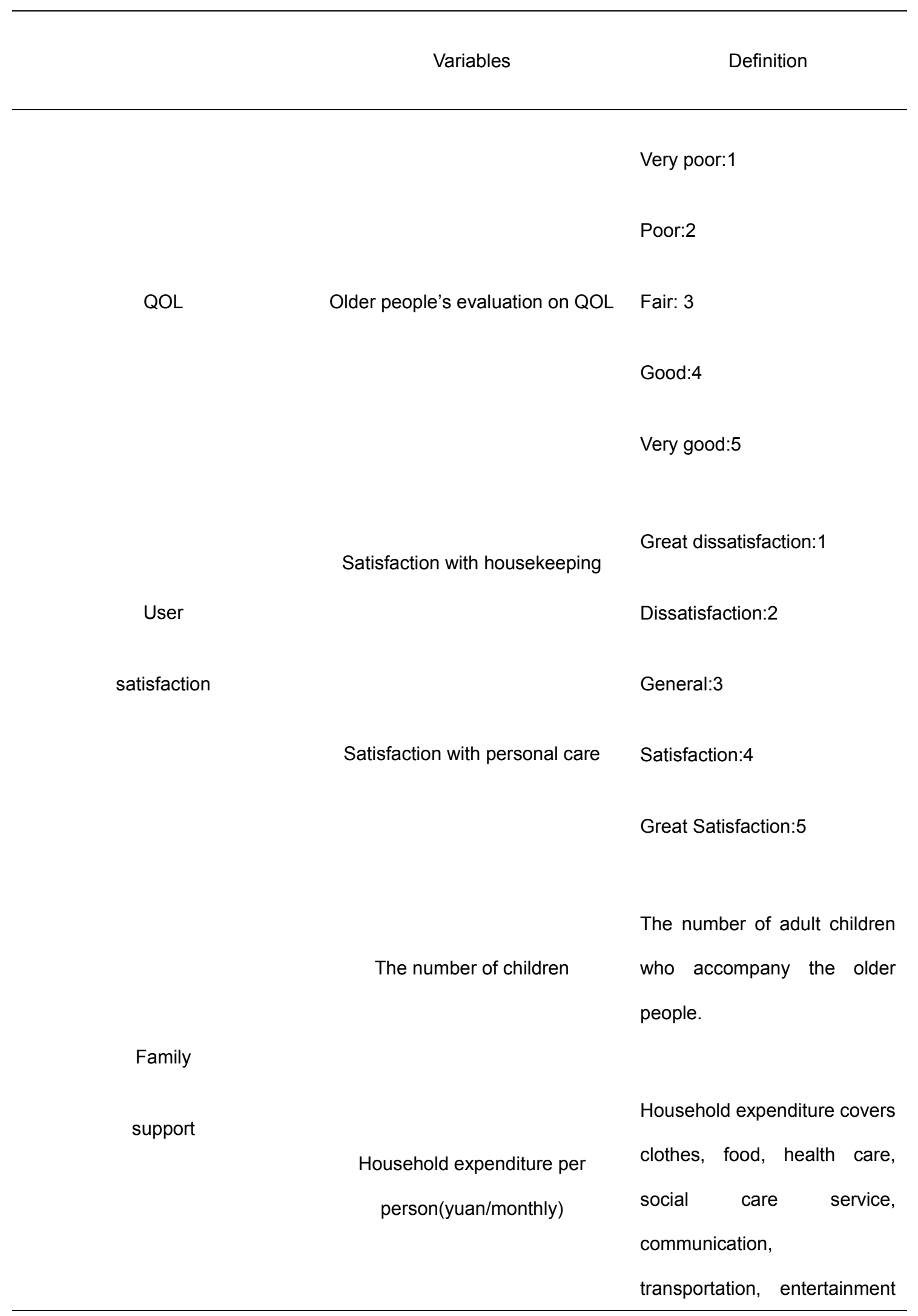


and other daily expenditure. It is divided by the number of household members.

Age

Recipients' actual age filled in the questionnaire.

Female:1

Gender

Male:0

Very good:1,

Good:2

Demographics

Health status

General:3

Poor:4

Very poor:5

Married:1

Non-married:0,includes the

Marital status single, windows and divorced.

Appendix C. Statistics on use of different kinds of services.

$\mathrm{N}$

$\%$
Number of services

used on average 
Housekeeping

Personal care

Both of them

Total
118

253

327

698
16.91

36.25

46.85

7.93(Total=17)

\section{References}

SHENG, LAIYUN. (2017). China Statistical Yearbook. Beijing: China Statistics Press.

BEIJING GOVERNMENT. 2015. Special Planning on Ageing service facilities in Beijing.

http://www.bjmzj.gov.cn/news/root/ghjh/2015-

11/115778.shtml?NODE_ID=root(accessed on November 25, 2015).

BEIJING GOVERNMENT. 2017. Report of Beijing Ageing career and service 2016-2017.

http://zhengwu.beijing.gov.cn/sy/bmdt/t1497329.htm (accessed on October 31, 2017).

ZILLER, ROBERT. (1974). "Self-Other Orientations and Quality of Life." Social Indicators Research 1(3), 301-327. http://www.jstor.org/stable/27521716. https://doi.org/10.1007/BF00303861

STIGGELBOUt, A. M., DE VOGEL-VOOGT, E., NOORDIJK, E. M., \& VLIET VLIELAND, T. P. M. (2008). "Individual quality of life: adaptive conjoint analysis as an alternative for direct weighting?" Quality of Life Research 17(4), 641-649. http://doi.org/10.1007/s11136008-9325-6

MASLOW \& ABRAHAM HAROLD \& ROBERT FRAGER \& JAMES FADIMAN. (1970) Motivation and personality. New York: Harper \& Row.

FRANK, M. \& ANDREWS \& WITHNEY, S,B. (1976) Social indicators of well-being: Americans' perceptions of life quality. New York: Plenum Press.

LARSON, R. (1978). "Thirty years of research on the subjective well-being of older Americans." Journal of gerontology 33(1), 109-125.

https://academic.oup.com/geronj/article/33/1/109/661221/Thirty-Years-of-Research-onthe-Subjective-Well. https://doi.org/10.1093/geronj/33.1.109

CALMAN, K.C.(1984). " Quality of life in cancer patients--an hypothesis." Journal of medical ethics 10(3): 124-127. http://jme.bmj.com/content/10/3/124.short. https://doi.org/10.1136/jme.10.3.124

BOWLING, A.(2001). Measuring disease: a review of disease-specific quality of life measurement scales. Philadelphia: The Philadelphia Press.

GALBRAITH. (1954). The Affluent Society. Shanghai: Shanghai People's Publishing Press.

CANGPING, WU. (2002) "A Scientific Understanding of Improving the Quality of Life of the 
Older." Population Research 30(5):1-5.

http://kns.cnki.net/KCMS/detail/detail.aspx?dbcode=CJFQ\&dbname=CJFD2002\&filena me=RKYZ200205000\&uid=WEEvREcwSIJHSIdRa1FhcEE0NXdoZ1FzNlgwRFhsWFF TSmxVYzFGaTNZWT0=\$9A4hF_YAuvQ5obgVAqNKPCYcEjKensW4ggl8Fm4gTkoUK alD8j8gFw!!\&v=MDQwNDdTNORoMVQzcVRyV00xRnJDVVJMMmZZT2RxRmlubVVy M09OeWJTZExHNEh0UE1xbzIGWkISOGVYMUx1eFk=

MIN LUO \& YUERAN, ZUO \& NINGING, JIN \& JING,ZHANG.,JIALIN,PENG. (2005). "Influence Factors of the Quality of Life of the Older in China and Countermeasures of Nursing Management." Nursing management Magazine 16(1):29-32.

http://kns.cnki.net/KCMS/detail/detail.aspx?dbcode=CJFQ\&dbname=CJFD2005\&filena me=HLGL200501011\&uid=WEEvREcwSIJHSIdRa1FhcEE0NXdoZ1FzNlgwRFhsWFFT SmxVYzFGaTNZWT0=\$9A4hF_YAuvQ5obgVAqNKPCYcEjKensW4ggl8Fm4gTkoUKal D8j8gFw!!\&v=MjlyOTVUcldNMUZyQ1VSTDJmWU9kcUZpbm1VNy9BTFNITVlyRzRIdF RNcm85RVpZUjhIWDFMdXhZUzdEaDFUM3E=

XIHUA, WANG \& HUAFA, ZHOU.(2010). "The Relationship between Quality of life in Older People, Loneliness and Subjective Well-being." China Journal of Gerontology 32(5): 676677.

http://kns.cnki.net/KCMS/detail/detail.aspx?dbcode=CJFQ\&dbname=CJFD2010\&filena me=ZLXZ201005045\&uid=WEEvREcwSIJHSIdRa1FhcEE0NXdoZ1FzNlgwRFhsWFFT SmxVYzFGaTNZWT0=\$9A4hF_YAuvQ5obgVAqNKPCYcEjKensW4ggl8Fm4gTkoUKal D8j8gFw!!\&v=MDU4MTBkcUZpbm1WcnpKUHIIVGRMRzRIOUhNcW85QIIZUjhIWDFM dXhZUzdEaDFUM3FUcldNMUZyQ1VSTDJmWU8=

BAILEY, V. (2007). "Satisfaction levels with a community night nursing service. "Nursing Standard 22(5):

35-42. http://journals.rcni.com/doi/abs/10.7748/ns2007.10.22.5.35.c4638

DALE,B \& SAVAREID, H.I \& KIRKEVOLD, M. (2010).“Older home nursing patients' perception of social provisions and received care." Scandinathroughn Journal of Caring Science 24(3), 523-532. http://onlinelibrary.wiley.com/doi/10.1111/j.1471-6712.2009.00744.x/full

DALE,B \& SAVAREID, H.I \& KIRKEVOLD, M. (2011). "Older Home-living Patients Perceptions of Received Home Nursing and Family Care. " Nordisk Sygeplejeforskning 1(3), 219-234. https://www.idunn.no/nsf/2011/03/art02?languageid=2

CROW, H \& GAGE, H \& HAMPSON, S.(2002). "Measurement of satisfaction with health care: Implications for practice from a systematic review of the literature." Health Technology Assessment 6, 1-24. http://uhra.herts.ac.uk/bitstream/handle/2299/1073/102382.pdf;sequence=1. https://doi.org/10.3310/hta6320

CURTIS, M.P \& SALES,A. E.B \& SULLIVAN, J.H.(2005) "Satisfaction with Care among Community Residential Care Residents." Journal of Aging and Health 17(1), 3-27. http://journals.sagepub.com/doi/abs/10.1177/0898264304268590

CHOU,S,C \& BOLDY,D,P \& LEE,A,H.(2003) "Factors Influencing Residents' Satisfaction in Residential Aged Care." The gerontologis 43(4), 459-472. https://academic.oup.com/gerontologist/article/43/4/459/592289/Factors-InfluencingResidents-Satisfaction-in

BERGLUND, A. L. (2007). "Satisfaction with Caring and Living Conditions in Nursing Homes: Views of Elderly Persons, Next of Kin and Staff Members." International Journal of Nursing Practice 13(1), 46-51. http://onlinelibrary.wiley.com/doi/10.1111/j.1440172X.2006.00602.x/full

WOODWARD, C. A \& ABELSON, J \& TEDFORD, S. (2004). "What is Important to Continuity in Home Care?: Perspectives of Key Stakeholdes." Social Science \& medicine 58(1), 
177-192. http://www.sciencedirect.com/science/article/pii/S0277953603001618. https://doi.org/10.1016/S0277-9536(03)00161-8

RAYNES, N. V \& COULTHARD, L.(2001). Quality at Home for Older People: Involving service users in defining home care specifications. Bristol: Policy Press.

BAIR, M. J \& KROENKE, K \& SUTHERLAND, J.M.(2007). "Effects of Depression and Pain Severity on Satisfaction in Medical Outpatients: Analysis of the Medical Outcomes Study." Journal of Rehabilitation Research and Development 44(2), 143. https://search.proquest.com/docview/215288223?pq-origsite=gscholar. https://doi.org/10.1682/JRRD.2006.06.0061

PARSONS, T.(2013). Social system. New York: Free Press.

MASLOW,A. H. (1943). "A theory of human motivation." Psychological review 50(4), 370. http://psycnet.apa.org/journals/rev/50/4/370/. https://doi.org/10.1037/h0054346 